ISBN 978-81-933894-1-6

International Conference on Studies in Disaster Management, Civil and Architectural Engineering

(SDMCAE-17)

Kyoto (Japan) April 18-19, 2017

\title{
Raising Disaster Awareness in Engineering Major Students through an Interactive Course
}

\author{
Nazan Akman Pek ${ }^{1}$, Yücel Torun ${ }^{1}$ \\ ${ }^{1}$ Earthquake Engineering and Disaster Management Institute \\ Istanbul Technical University, Maslak, Istanbul, Turkey
}

\begin{abstract}
Unique location of Turkey makes the country susceptible to various disasters such as earthquakes, floods, landslides etc. Engineers of tomorrow need to be aware of all the risks and consequences of disasters which increase both in numbers and economic and human losses. Disaster awareness is internalized through an elective undergraduate humanities course for all engineering major students. The course envelops all the aspects of disaster management and is concluded with the interactive town watching application. This study aims to show that by the end of the course, the students understand the disaster risks and make plans to decrease their vulnerabilities. Results of surveys conducted at the beginning and end of the course are presented. While the students learn about disasters, risks and resources at hand, they will also carry their knowledge on disasters to the various projects and designs they will build in the future and share it with friends and family. In conclusion, offering a humanities course on disaster awareness is not only beneficial on a daily basis for the students but also may help towards the countries resilience to disasters.
\end{abstract}

Keywords: disaster awareness, risk assessment, disaster education

\section{Introduction}

In the last 30 years, it has been noted that disasters increased in numbers as well as the number of people who are affected by them [1]. Apart from human loss, the economic impact of disasters on countries continues to have an impact globally as well. Turkey is no exception. In fact, recent earthquakes and floods have had their toll. See Table I.

TABLE I: Losses due to Natural Disasters in Turkey for the past 30 years

\begin{tabular}{lrrr}
\hline \multicolumn{4}{c}{ Natural Disasters in Turkey between 1986-2016* } \\
\hline \hline Date & Total damage ('000 US\$) & Total affected & Totals deaths \\
1992 & 750000 & 306617 & 261 \\
1995 & 205800 & 63015 & 74 \\
1998 & 1000000 & 348850 & 604 \\
1998 & 550000 & 252327 & 145 \\
1999 & 20000000 & 1589600 & 17127 \\
1999 & 1000000 & 1240047 & 653 \\
2006 & 317000 & 224948 & 135 \\
2009 & 550000 & 290520 & 177 \\
2011 & 244000 & 160240 & 94 \\
2011 & 1500000 & 1358953 & 845 \\
\hline \hline
\end{tabular}


Therefore, the importance of disaster awareness is undeniable. Even though, governments, local authorities fulfill their responsibilities on mitigation measures, risk reduction issues, the citizens must also be aware of the risks and consequences of disasters.

Universities, especially the ones offering engineering courses, are shaping the future of the world through brand new products, structures. Hence, engineers who have captured the importance of disasters will undoubtedly reflect their conceptions on disasters to their designs and innovations. In this context, the authors believe that a course concentrated on disaster awareness is vital.

Moreover, individual preparedness is also important. This paper aims to show that a disaster awareness course that utilizes an interactive town watching tool for engineering major students is crucial both for individuals and for the society.

\section{Curriculum of the Disaster Awareness Course}

At Istanbul Technical University, undergraduate students are free to choose many elective humanities course. All these courses help the engineering major students to enhance their worldview and non-engineering topics. Disaster awareness is one of these 3 credit courses offered each semester to all undergraduate students.

The course objectives are; to increase disaster awareness in society, to teach basic principles of emergency management, to be prepared for disasters as an individual, to recognize risks and resources concerning disasters and to be able to utilize them when necessary [2].

The topics covered are; disasters that are frequently encountered in Turkey, principles of integrated disaster management principles, current situation in Turkey from the point of view of disasters, current laws and regulations on disasters, preparing for disasters as an individual and as a society, importance and roles of volunteers, recognizing risks and resources.

After successfully completing this course, the students will understand the importance of disaster preparedness, have assimilated the four phases of emergency management, be able to determine the risks and resources around them and have an idea on how to use them and have comprehended the basis for voluntariness.

As is well known, the integrated disaster management has four major phases as shown in the Figure 1. This course is an example of mitigation efforts.

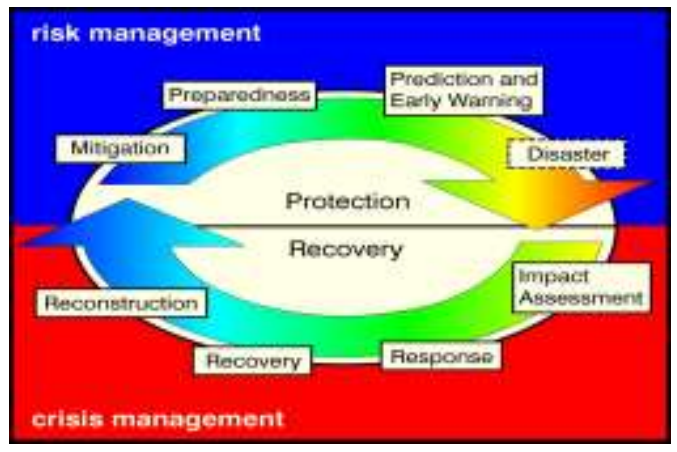

Fig. 1: Modern Disaster Management Cycle [3]

After having completed the course material, town watching technique is applied. Town watching technique was developed and implemented by Japanese urban planners in the 1970s [4]. This method, also called 'Machizukuri' movement, was developed as a planning technique aiming at the participation of the residents in city planning. Later on, town watching was applied to disaster related work where safe areas during disasters are identified and evacuation routes are determined [5,6]. In the context of the course, town watching technique is applied in three stages. First, the technique is explained to students and teams are formed. Teams are formed from 4-5 students where each team member has a specific role such as observing the resources or risks, reading map, taking photos and so on. Second stage involves field trip to various campuses of the university where students spend their time. During fieldwork, risks and resources that can be used following a disaster are marked 
on the map and photographs are taken. In short, the students look for threats and resources that may be of help after disasters in golden hours.

The final stage is where fieldwork is presented in class. After having completed the tour, all data obtained are marked on larger maps with the photos attached. Each team explains the area covered and the risks and resources that they have come across. A short DIG (DIsaster Game) is played on how to leave the campus if they are stranded in that part of the campus. After having completed town watching, most of the students quote that they were not aware of the threats and resources even though they walk through the campus each day.
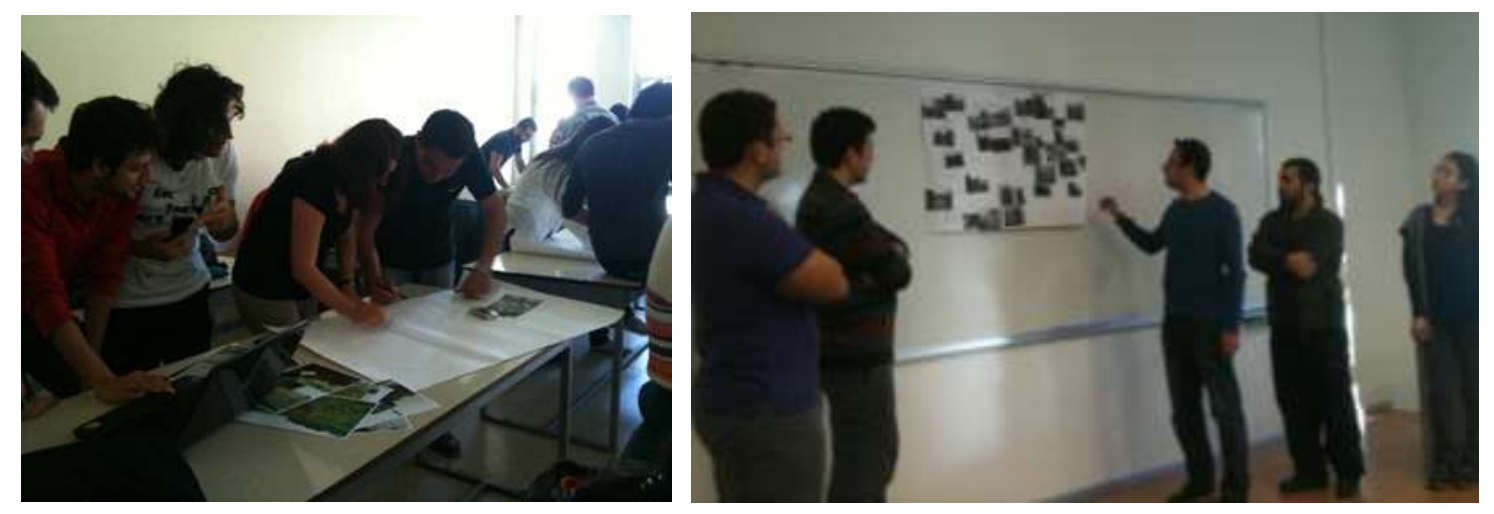

Fig. 2: Photos from various stages of town watching application

Their findings are discussed in class and a short DIG (DIsaster Game) is played on how to leave the campus if they are stranded in that part of the campus. After having completed town watching, most of the students quote that they were not aware of the threats and resources even though they walk through the campus each day.

In order to quantify the outcomes of the course, two surveys are handed to students; one at the beginning of the semester and one at the end of the semester. The results of both surveys are presented in the next section. The first survey is about preparedness on disasters and disaster experience. The second survey has questions on how to better prepare for disasters.

\section{Survey Results and Assessments}

First survey is designed to evaluate the students' reasons for choosing the course as well as their acquaintance with disasters. It is handed to students before the first lecture. The questions of the first survey are given in Table II:

TABLE II: QUESTIONS OF THE FIRST SURVEY

\begin{tabular}{ll}
\hline \hline Question & Question asked \\
\hline 1 & Why did you choose this course? \\
2 & Have you ever been in a disaster? \\
3 & Was a close relative/friend in a disaster? \\
4 & In your opinion, which disaster is most likely to affect your life? \\
5 & Do you know what to do during an earthquake? \\
6 & In your opinion, is the building you live in Istanbul durable? \\
7 & Do you have an evacuation plan from the building you live in Istanbul? \\
8 & Do you have an Emergency/Disaster Bag? \\
9 & Do you have smoke detectors in the building you live in Istanbul? \\
10 & Are there any measures that you take against disasters as an individual? \\
\hline \hline
\end{tabular}


Second survey aims to quantify the learning obtained by the end of the semester. Questions of the second survey are as follows:

TABLE III: Questions of the Second Survey

\begin{tabular}{|c|c|c|c|}
\hline $\begin{array}{l}\text { Que } \\
\text { stion } \\
\text { No }\end{array}$ & Question asked & & \\
\hline 1 & I have taken some precautions/preparatory actions for disasters. & Yes & No \\
\hline 2 & If you have marked "Yes", please indicate. (The following options are given) & & \\
\hline $2 \mathrm{a}$ & $\begin{array}{l}\text { I filled out an emergency card and carried it in my wallet, I shared the meeting places following a disaster } \\
\text { with my relatives and I informed my emergency contacts. }\end{array}$ & Yes & No \\
\hline $2 \mathrm{~b}$ & I prepared an evacuation plan and I know how to evacuate. & Yes & No \\
\hline $2 \mathrm{c}$ & I made an emergency plan. & Yes & No \\
\hline $2 \mathrm{~d}$ & I prepared an emergency case. & Yes & No \\
\hline $2 \mathrm{e}$ & I keep a flashlight and a whistle in my bedroom. & Yes & No \\
\hline $2 \mathrm{f}$ & I fixed my heavy furniture & Yes & No \\
\hline $2 \mathrm{~g}$ & I know how to act in a disaster / emergency situation. & Yes & No \\
\hline $2 \mathrm{~h}$ & I bought a smoke detector. & Yes & No \\
\hline $2 \mathrm{i}$ & I bought a fire extinguisher. & Yes & No \\
\hline $2 \mathrm{j}$ & 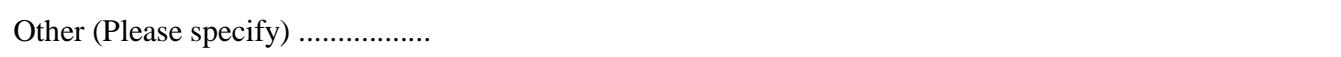 & Yes & No \\
\hline 3 & I can identify risks that will affect me & Yes & No \\
\hline 4 & I know how to turn off sources like water / electricity / natural gas where I live. & Yes & No \\
\hline 5 & This course raised disaster awareness level. & Yes & No \\
\hline 6 & I think this course is useful. & Yes & No \\
\hline 7 & I have shared this learning with others. & Yes & No \\
\hline 8 & I plan to receive first aid training. & Yes & No \\
\hline
\end{tabular}

The results of the surveys presented in this paper cover the data collected in 5 academic years. 181 students have completed the surveys. These engineering students are from the following engineering programs:

- Civil Engineering

- Mechanics Engineering

- Electrical - Electronics Engineering

- Mine Engineering

- Chemical and Metallurgical Engineering

- Computer and Informatics

- Naval Architecture and Ocean Engineering

- Aeronautics and Astronautics Engineering

A summary of the demographic part of the survey is as follows: $73 \%$ of the participating students were male and $27 \%$ were female. The ages varied from 18 to 33 and the average student age was 22.7. 130 students are from Istanbul and the rest reside in other cities of Turkey. During academic year, $20 \%$ of the students live in dorms, $32 \%$ of the students rent apartments with their friends and $48 \%$ of the students stay with their families.

The rest of the first survey's results examine the disaster knowledge and willingness for the course. The results are presented in following figures. 


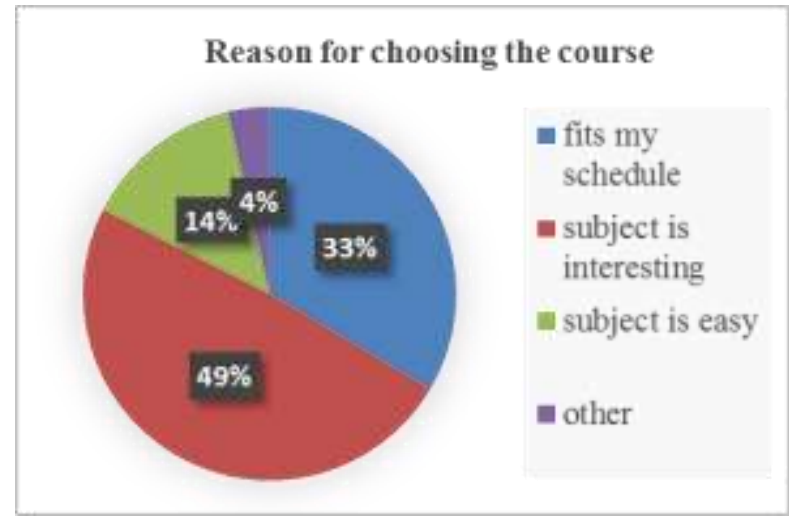

Fig. 3: Distribution of the reasons for selecting course
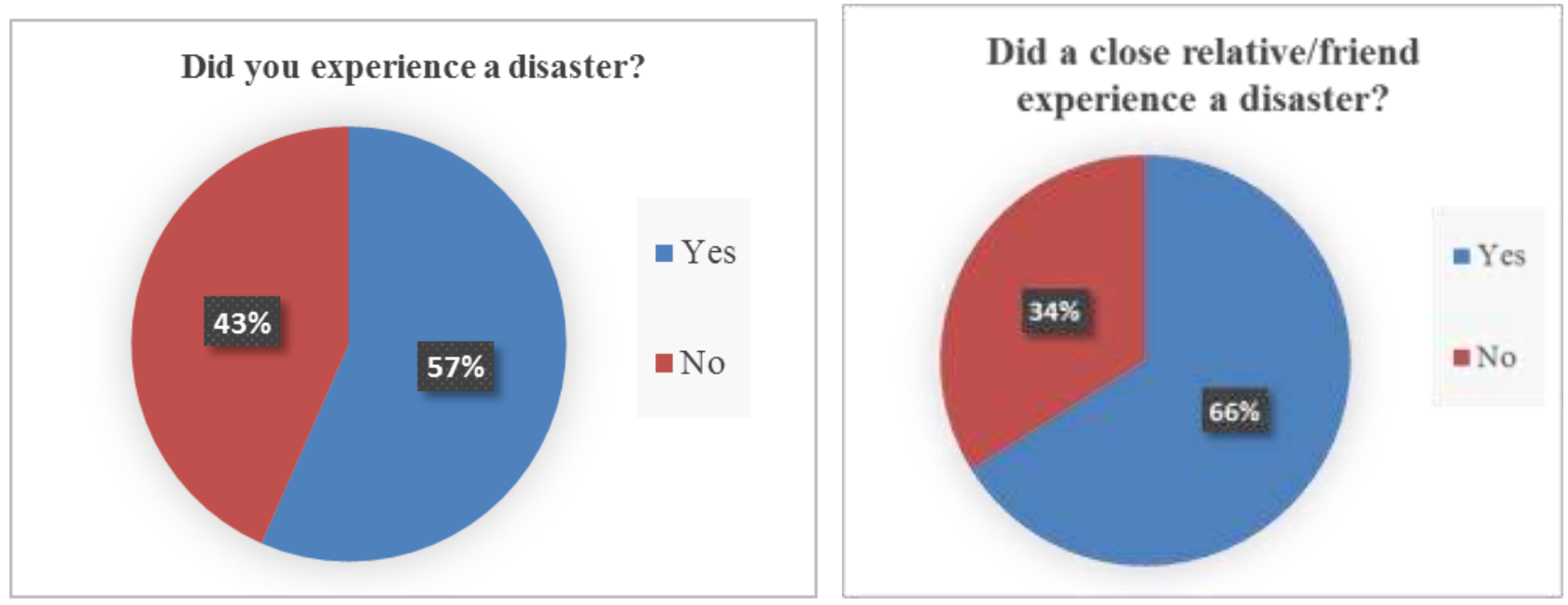

Fig. 4: Percentage of students, relatives/friends experiencing disaster

$57 \%$ of the students were in a disaster. $97 \%$ of these students experienced earthquake, $2 \%$ experienced flood, $1 \%$ experienced landslide, $1 \%$ experienced fire and $1 \%$ experienced terrorism event. Similarly, $66 \%$ of the students stated that someone from their family of friends experienced a disaster. $89 \%$ of these students' relatives or friends experienced earthquake, $1.5 \%$ experienced flood, $2.5 \%$ experienced fire and $1 \%$ experienced terrorism event.

Furthermore, $73 \%$ of the students think that earthquake is the most likely disaster to affect their lives in the future whereas $17 \%$ believe that drought, $4.5 \%$ flood, $4.5 \%$ other disasters. Comparing the percentages of question 1 with question 2 and 3, it can be argued that the students who thought the subject was interesting may overlap with the students who experienced a disaster.

The rest of the survey covers the awareness of the students with basic questions on what to do during an earthquake, building resilience, and precautionary measures: $81 \%$ of the students claim to know what to do during an earthquake, $60 \%$ believe that the building that they live in is earthquake resilient. Only $17 \%$ of the students have an evacuation plan, $14 \%$ have an emergency bag, $25 \%$ have a smoke detector where they live and $25 \%$ state that they made some precautionary measures such as fixing furniture, keeping a flashlight, knowing their muster area etc.

It can be easily seen that more than half of students participating in the survey have experienced a disaster. The majority have been in an earthquake. Similarly, the majority believe that the disaster that will most likely to affect their lives in the future is earthquake, followed by drought. Given the fact that most of Turkey is on fault lines, these results are not surprising. However, only $15-25 \%$ of the students have thought about taking simple precautionary actions. 
Second survey aimed at the learning outcomes and disaster awareness levels is conducted at the end of the semester. Results are summarized in the tables IV and V.

TABLE IV: Results of the Second Survey

\begin{tabular}{lc}
\hline \hline Question & $\begin{array}{c}\text { Percentage of } \\
\text { "Yes" }\end{array}$ \\
\hline I have taken some precautions/preparatory actions for disasters. & 96 \\
I can identify risks that will affect me & 86 \\
I know how to turn off sources like water / electricity / natural gas where I live. & 99 \\
This course raised disaster awareness level. & 99 \\
I think this course is useful. & 99 \\
I have shared this learning with others. & 88 \\
I plan to receive first aid training. & 77 \\
\hline \hline
\end{tabular}

TABLE V: Type of Preparatory Actions Taken

\begin{tabular}{lc}
\hline \hline Question & $\begin{array}{c}\text { Percentage of } \\
\text { "Yes" }\end{array}$ \\
\hline $\begin{array}{l}\text { I filled out an emergency card and carried it in my wallet, I shared the } \\
\text { meeting places following a disaster with my relatives and I informed my } \\
\text { emergency contacts. }\end{array}$ & 100 \\
I prepared an evacuation sketch and I know how to evacuate. & 84 \\
I made an emergency plan. & 70 \\
I prepared an emergency case. & 29 \\
I keep a flashlight and a whistle in my bedroom. & 49 \\
I fixed my heavy furniture & 34 \\
I know how to act in a disaster / emergency situation. & 80 \\
I bought a fire extinguisher. & 7 \\
\hline \hline
\end{tabular}

The survey outcomes show that the course was a success in raising disaster awareness in engineering major students. They have learnt to identify disaster risks and resources, shared their knowledge with others. Some of them are even eager to learn extra skills such as first aid.

\section{Conclusion}

The humanities undergraduate course tailored to convey an introduction to modern disaster management, increase disaster awareness is beneficial especially for engineering major students. Future engineers must realize that the disasters are increasing and the disaster toll is high for citizens, governments alike. The economic welfare is also at stake. Moreover, the citizens themselves should be able to identify the threats and resources. For the above-mentioned reasons, a course named "Disaster Awareness" has been offered in Istanbul Technical University since 2012. The curriculum of the course is included in this paper along with the interactive town watching technique that is helpful in applying theoretical knowledge into practice. The learning outcomes and level of disaster awareness is quantified with two surveys conducted at the beginning and end of the semester. The results show that a majority of the students has become aware of the risks involving disasters and are eager to take precautionary actions. Many students admit that they notice risks and resources in the campus for the first time during their town watching application. They have noticed details in the designs of structures and other related materials that may either hinder or enhance mitigation efforts for disasters. 


\section{References}

[1] D. Guha-Sapir, R. Below, Ph. Hoyois - EM-DAT: The CRED/OFDA International Disaster Database - www.emdat.be - Université Catholique de Louvain - Brussels - Belgium.

[2] N. Akman Pek, Disaster Awareness Lecture Notes (in Turkish), published on ninova e-learning platform, 2016 Available: http://ninova.itu.edu.tr/Ders/2345/Sinif/22181/Dosyalar.

[3] D. Alexander, Principles of Emergency Planning and Management. Oxford University Press. 2002, p.6.

[4] Y. Ogawa, A.L. Fernandez, T. Yoshimura, 2005, "Town Watching as a tool for citizen participation in Developing Countries: Applications in Disaster Training”, International Journal of Mass Emergencies and Disasters, V23, No.2, pp.5-36, 2005.

[5] İ.H. Helvacioğlu, Y. Ogawa, "Town Settlement Analysis (Town Watching) Site Survey Applications" (in Turkish), in Basic Principles of Reducing Disaster Damage, Ed.s M. Kadığlu, E. Özdamar, JICA Turkey Office Publ. No.2, 2008, pp.79-90.

[6] Ünlü A., “As a Risk Assessment Model: Town Watching” (in Turkish),in Principles of Disaster Management, Ed.s M. Kadıoğlu, E. Özdamar, JICA Turkey Office Publ. No.1, 2006, pp.53-59. 